\title{
Assessment of the Teaching Behavior of the Instructors of an Out-of-School Program
}

\author{
Elena Rodríguez-Naveiras ${ }^{1, *} \&$ África Borges ${ }^{1}$ \\ ${ }^{1}$ Clinical Psychology, Psychobiology and Methodology Department, Psychology Faculty, University of La Laguna, \\ 38250 La Laguna, Spain \\ *Correspondence: Clinical Psychology, Psychobiology and Methodology Department, Psychology Faculty, \\ University of La Laguna, 38250 La Laguna, Spain. Tel: 34-922-317-572. E-mail: naveiras@ull.es
}

Received: March 30, 2015 Accepted: May 4, 2015 Online Published: May 14, 2015

doi:10.5430/jct.v4n1p145 URL: http://dx.doi.org/10.5430/jct.v4n1p145

\begin{abstract}
Out-of-school programs for students with high abilities are especially relevant when their needs are not covered in formal education. The evaluation of these programs is essential and it can be carried out from different evaluative approaches. The evaluation of the behavior of the people who implement the programs is an important aspect in the evaluation of process and it can resemble the one conducted by a teacher in formal education. This type of assessment requires an appropriate methodology such as the observational. In this study a protocol for observation of teaching functions has been designed for the evaluation of the behavior of the instructors of a socio-affective out-of-school program. The frequency of occurrence of behaviors as well as the resultant of conducts in intrapersonal, interpersonal and cooperative activities is analyzed in this study.
\end{abstract}

Keywords: high ability children; out-of-school programs; programs evaluation; observational methodology

\section{Introduction}

From the scientific perspective, the need to create and develop programs of intervention at any level requires an evaluation process to know their effectiveness and assessment. Program evaluation is a continuous and systematic methodological process that can be performed at any moment of the development of the program, or during all of them: evaluation of the units, evaluation of planning and the theory of the program, evaluation of the implementation, impact assessment and evaluation of costs (Rossi, Lipsey \& Freeman, 2004). This scientific procedure will allow to verify the systematic effectiveness of the action to subsequently make decisions about possible changes in the program, including the improvement of the conditions of the program, removing some of its components, etc.

In the program evaluation, despite the different positions and approaches, there are key elements that describe it: the dynamic nature of the evaluation, the scientific process, the collection of valid and reliable information, the decision-making, the contextualized nature; being referred to a program; having an ideological and political function and enabling an assessment of what it has evaluated (Colás \& Rebollo, 1993; Newcomer, Hatry \& Wholey, 2010).

Program evaluation can be performed through many different ways and many different approaches. Given the diversity of programs that exist, the program evaluation meets different criteria when it comes to classifying the evaluation that is being carried out, such as: depending on the purpose of the evaluation (summative and formative evaluation); the time in which the evaluation is performed (ex-ante evaluation, during evaluation and final evaluation); the person who performs the assessment (external, internal, mixed) and formal and substantive assessment (Borges \& Rodríguez-Naveiras, 2012).

Depending on the objective of assessment, a common classification at the time of evaluating a program is that which differs by the objectives pursued in the assessment, distinguishing between summative and formative assessment (Veney \& Kaluzny, 1984; Aguilar \& Ander-Egg, 1992; Shiratuddin \& Landoni, 2002): a) Summative evaluation responds to the question of whether the program is reaching the goals, and whether these goals are the results of the program, b) On the other hand The formative evaluation or process assesses the implementation of the program and allows you to make changes as it evaluates the needs, gaps and difficulties observed in the goals.

In the evaluation of process the degree of participation of those involved, how the programmed actions are being 
carried out and the behavior of the staff running the program can be analyzed (López de la Llave \& Pérez-Llantada, 2004).

The evaluation of process aimed at the assessment of high ability programs allows us to study in detail their essential components. The figure of the psycho-educational instructor in this type of program is similar to a teacher, since it is developed in the context of formal education, and out-of-school intervention programs also require teaching assignments for socio-affective contents.

It is important to note that there is a clear similarity between the work of teachers in the teaching-learning process and the instructors who develop a psychoeducational intervention program, because they both perform actions that seek to achieve educational goals in a formal context. (Brophy \& Evertson, 1976; Hernández, 1991; Hernández \& García, 1991; Cooper, 1993; Justicia, 1996; Guerrero, 2009; Romero, 2010)

In out-of-school intervention for high ability programs, the instructor has a fundamental role to develop activities of a socio-affective content, aiming to prevent or improve various socio-emotional adjustment problems that people with high abilities may have. The educational enrichment programs of an affective perspective represent an alternative to the development of the capacities of children with high abilities (Renzulli, 1977; Alonso \& Benito, 1996; Prieto \& Ferrándiz, 2001; Díaz \& Bravo, 2002; Arancibia, Lissi \& Narea, 2008; Rodríguez-Naveiras, 2011; Borges \& Rodríguez-Naveiras, 2012; Borges \& Rodríguez-Naveiras, 2014). The objectives of the socio-affective enrichment programs include:

-Intrapersonal aspects: To promote social-emotional development through factors such as self-esteem, self-concept, emotions, skills to deal with feelings, etc.

-Interpersonal aspects: To develop social skills: listening, dialogue, negotiation, decision-making.

-Cooperative aspects: To promote behaviors of cooperation, teamwork, respect for others.

For the evaluation of the behavior of the instructor in an out-of-school program, the observational methodology allows to rigorously and flexibly determine not only the educator's behavior, but also, and more importantly, how their interaction with students is as well as its quality. This allows us to extract relevant behavioral patterns to improve the program.

The evaluation of teachers through observation instruments dates back to the 1960s, in which instruments for that purpose began being designed (Flanders, 1961; Tricket \& Moos, 1974; Evertson \& Anderson, 1978; Houtveen, Booij, de Jong \& Van de Grift, 1999; Van de Grift, 2007; Watkins \& Biggs, 1996; Rodríguez \& Ibarra, 2013; Rodríguez-Naveiras, Borges \& Cadenas, 2013; Díaz-Hernández, 2014). Regarding teachers who work with high ability students, there have been some studies where they have designed observational instruments that assess the process and the teacher's behavior inside the classroom, in order to introduce improvement plans (Kulieke, 1986; Feldhusen \& Hoffman, 1988; Cassady, Neumeister, Speirs, Cheryl \& Cross, 2004; VanTassel-Baska, Quek \& Feng, 2007; Rodríguez-Naveiras, 2011).

In this research the instrument Observation Protocol of Teaching Functions (PROFUNDO, v2) (Rodríguez-Naveiras, 2011) has been used to evaluate the behavior of the instructors of an out-of-school program. The objective of this research is to evaluate the conduct of the instructor of a high ability program by analyzing their behavior and interaction with participants, checking if their behavior is different depending on the type of activity (intrapersonal, interpersonal and cooperative) that is being developed in the program.

\section{Method}

\subsection{Methodology and Design}

An observational methodology has been followed, based on the different units of studies. On one hand, a nomothetic design has been used in the analysis of the group of instructors. On the other hand, an idiographic design was used in the analysis of each instructor. According to the temporal axis this is a followed study because it has been carried out throughout all the sessions in the program. According to the dimension axis, this is a multidimensional study because it is focused on the teaching functions divided into macrocategories, criteria and codes (Anguera, Blanco \& Losada, 2001).

\subsection{Participants}

The participants of this study are the children who took part in the Program for the Complete Development of High Ability Children (PIPAC) (Borges \& Rodríguez-Naveiras, 2014) developed during the academic year 2006/2007. In 
particular in one level of intervention: "the preadolescent level" made up by nine boys and three girls aged from 10 to 12 years old.

The second group of participants is made up by the instructors who implemented the program. Each level of intervention was guided by two instructors; a main instructor who was responsible for the program (in this case, a 25 year old for "the preadolescent level", with a degree in Psychology) and a secondary instructor who helped with the main instructor's task (a 19 year old student of Psychology for "the preadolescent level").

The coding of the instructors and the participants' behavior was done by six observers; five women and one man between 19 and 29 years old. All of them were students or they had a degree in Psychology. Also, they were trained by the expert observer and they passed the reliability index which is a guarantee of the quality of the data.

\subsection{Procedure}

This research focuses on the behaviors of the instructors and participants in the Program for the Complete Development of High Ability Children (PIPAC) in its fourth edition, conducted between October 2006 and June 2007 in the University of La Laguna. PIPAC is an out-of-school program with a socioaffective profiles aimed at children from 4 to 12 years of age and their families.

Intervention with children takes place in the subprogramme "Discovering ourselves" which is divided into age levels: level 1 for boys and girls from 4 to 6 years; level 2 for those who are between 7 and 9 years, and finally, level 3 for those aged 10-12 years. The program includes their parents in other specific subprogramme "Meetings" of parent's school which is carried out on the same day and at the same time that the program for children.

Sessions are bi-weekly. They last from 60 to 90 minutes and use recreational activities that include three types of contents which are developed along three quarters: intrapersonal, interpersonal and cooperative.

To select the sessions three criteria were taken into account: a) three sessions in a four-month period were chosen, b) each selected sessions of the program were clearly observable and did not present difficulties when it comes to coding behaviors and c) that the sessions would represent activities in which intrapersonal, interpersonal and cooperative contents are developed. The table number 1 presents the socio-affective contents developed in the preadolescent level of the PIPAC program.

For this research, nine sessions of the preadolescent level in the PIPAC program were selected.

Table 1. Contents Developed PIPAC Program Sessions

\begin{tabular}{cc}
\hline Sessions & Contents \\
\hline A & Tolerance \\
B & Negotiation \\
C & Self-esteem \\
D & Team work \\
E & Learn how to work in a group \\
F & Self-concept \\
G & Assertiveness \\
H & The person in the group \\
I & Group work, final presentation \\
\hline
\end{tabular}

\subsection{Instrument}

\subsubsection{Observation Protocol in the Teaching Functions (PROFUNDO, v2)}

In order to assess the instructors' behavior in the PIPAC program, the work and research group in high abilities at La Laguna University developed an ad hoc observational instrument called Observation Protocol of Teaching Functions (PROFUNDO, v2) (Rodríguez-Naveiras, 2011) based on the combination of field formats and category systems (Blanco, Castellano, Hernández Mendo, Anguera, Ardá \& Camerino, 2006 named by Gil Galve, 2008).

It is an observational instrument which is categorized and composed of a generic scope which includes six macro-categories based on Hernández-Jorge's (2005) teaching functions: organization function, teaching communicative function, behavioral control function, motivation function, orientation and assessment function and interaction function. These macro-categories are divided in 10 criteria, which are an accurate specifications of them, operating with 20 observable behavioral codes.

To complete the constant flow of the instructors' behavior, it is necessary to include an instrumental category which 
collects both unobservable behavior (those which are not in the scope of the camera) and other types of behavior (those which are not connected to the teaching functions). (see chart 1).

Chart 1. Observation Protocol in the Teaching Functions (PROFUNDO), second version

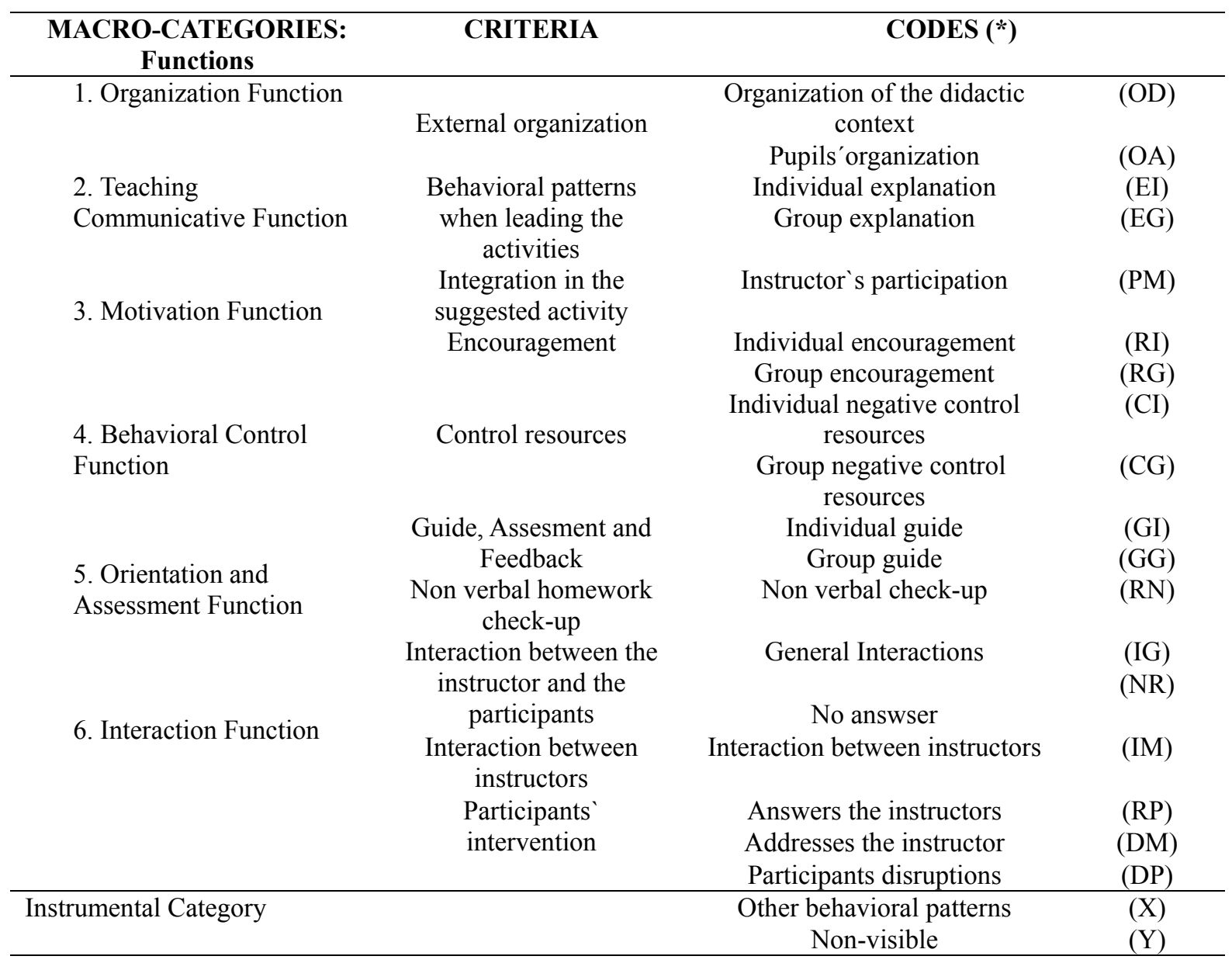

* The codes' abbreviations are written according to the original Spanish names.

\subsection{Registry and Encoding Instruments}

The intervention sessions were recorded on video with a recording equipment consisting of a GZ-MG20E camera JVC video lens, under both the parents' and the instructor's authorizations. The software Theme-Coder (Borrie, Jonsson \& Magnusson, 2001) was used to code the behaviors.

\subsection{Data Analysis}

The statistical analysis program SPSS (version 17.1) was used for the analysis of frequencies, and the SDIS-GSEQ, v. 4.2.0. (Bakeman \& Quera, 1996) for sequential studies. The data was analyzed in groups, taking into account the total of interpersonal, interpersonal and cooperative activities. It is a synthesizing and global study.

\section{Results}

\subsection{Macroanalysis}

The analysis of the data began with the measurement obtained from an observational recording. The relative frequencies that are the basis of subsequent sequential analysis are presented to describe the global codes of behavior and teaching functions of the instructors and participants of the two levels of intervention.

Below are the results for the study at the descriptive level, showing the relative frequency of each code for the developed areas (intrapersonal, interpersonal and cooperative) in order to have a global vision of the codes in the pre-adolescent level. To facilitate the expositional clarity only two decimals are given. They will have a value of 0 when the conduct is not present. The relative frequencies exceeding 0.10 have been put in bold. 
The relative frequencies of the codes are shown in table 2 for the main and secondary instructors, as well as participants from the preadolescent level (main instructor (M-I), secondary instructor (S-I) and participants (P)).

Table 2. Relative Frequencies for the Codes of the Preadolescent Level (Intrapersonal, interpersonal and cooperative area)

\begin{tabular}{ccccccccccc}
\hline \multirow{2}{*}{ Codes } & \multicolumn{3}{c}{ Intrapersonal } & \multicolumn{3}{c}{ Interpersonal } & \multicolumn{3}{c}{ Cooperative } \\
\cline { 2 - 10 } & M-I & S-I & P & M-I & S-I & P & M-I & S-I & P \\
\hline OA & 0.00 & 0.01 & -- & 0.01 & 0,00 & -- & 0.00 & 0.01 & -- \\
OD & 0.00 & 0.01 & -- & 0.01 & 0,00 & -- & 0.00 & 0.00 & -- \\
EI & 0.00 & 0.00 & -- & 0 & 0 & -- & 0 & 0 & -- \\
EG & 0.00 & 0.00 & -- & 0.00 & 0,00 & -- & 0.00 & 0.00 & -- \\
PM & 0.00 & 0.00 & -- & 0.00 & 0,00 & -- & 0.01 & 0.01 & -- \\
IM & 0.03 & 0.03 & -- & 0.02 & 0,02 & -- & 0.03 & 0.03 & -- \\
RI & 0.01 & 0.01 & -- & 0.01 & 0,00 & -- & 0.01 & 0.01 & -- \\
RG & 0.00 & 0.00 & -- & 0.00 & 0,00 & -- & 0.00 & 0.00 & -- \\
CI & 0.00 & 0.00 & -- & 0.01 & 0,01 & -- & 0.00 & 0.00 & -- \\
CG & 0.00 & 0.00 & -- & 0.00 & 0,00 & -- & 0.00 & 0.00 & -- \\
GI & $\mathbf{0 . 2 2}$ & $\mathbf{0 . 1 8}$ & -- & $\mathbf{0 . 2 5}$ & $\mathbf{0 , 1 2}$ & -- & $\mathbf{0 . 1 6}$ & $\mathbf{0 . 1 6}$ & -- \\
GG & 0.06 & 0.04 & -- & $\mathbf{0 . 1 0}$ & 0,03 & -- & 0.09 & 0.06 & -- \\
RN & 0.00 & 0.00 & -- & 0.00 & 0,00 & -- & 0.00 & 0.00 & -- \\
X & 0.00 & 0.00 & -- & 0.00 & 0,00 & -- & 0.00 & 0.00 & -- \\
Y & 0.01 & 0.01 & -- & 0.01 & 0,02 & -- & 0.01 & 0.00 & -- \\
IG & 0.00 & 0.00 & 0.00 & 0.00 & 0,00 & 0.00 & 0.00 & 0.00 & 0.00 \\
NR & 0.00 & 0.00 & 0 & 0.00 & 0,00 & 0 & 0.00 & 0.00 & 0 \\
DM & -- & -- & $\mathbf{0 . 0 9}$ & -- & -- & $\mathbf{0 . 1 2}$ & -- & -- & $\mathbf{0 . 1 0}$ \\
RP & -- & -- & $\mathbf{0 . 1 4}$ & -- & -- & $\mathbf{0 . 1 4}$ & -- & -- & $\mathbf{0 . 1 6}$ \\
DP & -- & -- & 0.00 & -- & -- & 0.01 & -- & -- & 0.01 \\
\hline
\end{tabular}

The codes that have higher relative frequencies are Individual Guide (GI), Group Guide (GG), Addresses the Instructor (DM), Answers the Instructor (RP) and Interaction between Instructors (IM).

\subsection{Microanalysis}

An analysis was performed from the perspective of microanalysis to study the relations between units of behavior using the sequences of behavior, because it is the most widespread approach based on the sequential analysis.

For the sequential analysis of lag, the program SDIS-GSEQ, v. 4.2 .0 was used (Bakeman \& Quera, 1996). It is based on sequential data of event, getting the remain in lag one $(p<0.05)$.

Method of lag, which serves to detect patterns of behavior (Sackett, 1979), is based on determining whether behavior sequences appear simply by chance. To do so, behavior criteria was chosen which determines what behavior follows it first in the first lag, and which one appears in second place in the second lag. It is considered excitatory or positive dependence when $\mathrm{Z}$ is greater than 1.96 and negative, when $\mathrm{z}$ is less than -1.96.

In this research, behavior criteria will be determined by three types of agents: main instructor (M-I), secondary instructor (S-I) and participants (P), who have been selected based on their relative frequency, whereas the conduct as a criteria was selected when its relative frequency is greater than 0.10 .

\subsubsection{Intrapersonal Preadolescent Level}

When analyzing the instructors' behavior at the preadolescent level, four out of the twenty behavioral codes are considered as antecedent behavior in the analysis made for the intrapersonal activities. These four behaviors are the ones which appear more frequently, therefore they are considered as antecedents. They are shown in chart number 3 : Individual Guide (GI), Group Guide (GG) (both of which are found in the main instructor), Answers the Instructor (RP) and Addresses the Instructor (DM). 
Table 3. Preadolescent Level (Intrapersonal area, results by codes)

\begin{tabular}{|c|c|c|c|}
\hline \multirow{2}{*}{$\begin{array}{c}\text { Teaching } \\
\text { Functions }\end{array}$} & \multirow{2}{*}{$\begin{array}{c}\text { Antecedent } \\
\text { behavior }\end{array}$} & \multicolumn{2}{|c|}{ Consequent behavior } \\
\hline & & Lag 1 & Residual \\
\hline \multirow{4}{*}{$\begin{array}{c}\text { Assessment } \\
\text { Function }\end{array}$} & GI M-I & RP P & 14.981 \\
\hline & \multirow{3}{*}{ GG M-I } & EG M-I & 2.276 \\
\hline & & GG S-I & 2.764 \\
\hline & & $\mathrm{DM} \mathbf{P}$ & 4.561 \\
\hline \multirow{4}{*}{$\begin{array}{l}\text { Interaction } \\
\text { Function }\end{array}$} & \multirow{3}{*}{$\mathrm{DM} \mathbf{P}$} & EI M-I & 3.678 \\
\hline & & GI S-I & 8.859 \\
\hline & & X M-I & 2.235 \\
\hline & RP P & GI M-I & 15.642 \\
\hline
\end{tabular}

The Assessment Function includes orientation and guidance given by the instructor in the moment in which the participants are doing the activity. There are the Individual Guide (GI) and Group Guide (GG).

When the main instructor gives an Individual Guide (GI), this is a personal guide to a participant to asses and guide them in the activity that they are doing. It is followed by behaviors of interaction of the participants with a higher probability than chance. The interaction of the participants with the main instructor is Answers to the instructor (RP) before a guide that she has given through the code Individual Guide (GI).

The second antecedent behavior is Grupal Guide (GG) of the main instructor. The guides and assesment by the instructor of the group of boys and girls generate more consequent behaviors than in the former case. The Group Guide (GG) is followed by the behaviors of Group Explanation (EG) and the same behavior by the secondary instructor (Group Guide, GG) with a probability higher than chance. This means that once the main instructor assesses the group, the secondary instructor presents the same behavior.

Finally, the Group Guide (GG) is followed by the students' participation like Addresses the Instructors (DM). This means that when the instructor guides the group, the students address the instructors to make a question related to the activity on which they are working, with a probability higher than chance.

The responsibility of the group lies only in the main instructor as she is the one who performs the individual and group guides which generate answers in the participants. It is important to highlight the appearance of the explanation to the group in this type of the activities. These explanations are given to the whole group to give instructions on how to do the activities.

The secondary instructor does not show enough types of behavior to be considered as antecedent behavior. This instructor only performs group guides after the main instructor has guided the group in the first lag. This is the moment when she encourages the participants in the second lag.

When the participants' patterns are analyzed, the antecedent behaviors Addresses the Instructor (DM) and Answer the Instructor (RP) (which belong to the Interaction Function) generate a great quantity of the consequent behaviors in the two instructors in a first lag.

When the participant addresses the instructor (DM) to ask them some question about the activity that the instructor is doing, consequent behavior are generated by the main instructor like Individual Explanation (EI), Individual Guide (GI) and other behavioral patterns (X). These behaviors are adequate because after the participant addresses the instructor she explains or guides them in what they are doing.

The participants' types of behavior are followed by the explanations or guides from the main instructor in the first lag.

\subsubsection{Interpersonal Preadolescent Level}

The results of the activities in which the interpersonal area is developed show the same antecedent behavioral patterns which have been seen throughout the analysis done.

The main instructor's antecedent behavioral patterns and the childrens' participation behavioral patterns are going to generate a wider behavioral pattern than the one given in the previous analysis (table 4). 
Table 4. Preadolescent Level(Interpersonal area, results by codes)

\begin{tabular}{cccc}
\hline \multirow{2}{*}{ Teaching } & \multirow{2}{*}{ Antecedent behavior } & \multicolumn{2}{c}{ Consequent behavior } \\
\cline { 3 - 4 } & \multirow{3}{*}{ GI M-I } & Lag 1 & Residual \\
\hline & & OD M-I & 2.453 \\
& & NR P & 2.337 \\
\cline { 3 - 4 } Assessment & & RP P & 24.205 \\
Function & & OA M-I & 2.177 \\
& & RN M-I & 5.380 \\
& \multirow{2}{*}{ GG M-I } & CI S-I & 2.606 \\
& & GG S-I & 4.761 \\
& & DM P & 5.507 \\
Interaction & & RP P & 5.004 \\
Function & & EI M-I & 3.917 \\
& \multirow{3}{*}{ DM P } & GI M-I & 11.455 \\
& \multirow{2}{*}{ RP P } & X M-I & 2.424 \\
\hline & & GI M-I & 23.842 \\
& & GG M-I & 2.886 \\
\hline
\end{tabular}

The Assessment Function includes behaviors of individual guides and guide group only by the main instructor. This means that the main instructor generates a large amount of conducts of assessment so that they can be taken as antecedent behavior.

The consequent behavioral patterns that are generated more often after the antecedent behavioral patterns are: No Response (NR), Individual Control (CI), Pupils' Organization (OA) and Non Verbal Revision (RN). These ones do not appear in the analysis done in the interpersonal activities, whereas the rest of the behavioral patterns remain.

The behavioral patterns that are found in this type of activities are similar to those obtained in the intrapersonal area. However, the antecedent behavioral patterns lead to a higher number of consequent behavioral patterns due to the type of activities developed in this area.

When the antecedent behavior is Group Guide (GG) by the main instructor (assessing the group's behaviors as they develop activities) this behavior generates a large amount of consequential behaviors in a first lag. The behaviors that are generated are Pupils' Organization (OA), Non Verbal Review (RN), group guide of the secondary instructor (GG) and response behaviors in participants (DM, RP).

The Interaction Function includes the behavior of the participants. When the antecedent behavior is the behavior addresses the instructor (DM), this behavior generates a consequent behavior in the main instructor who responds to the participant guiding them in the teaching-learning process (GI) or giving an explanation of the activity (EI).

When antecedent behavior is Answers of the participant (RP) this behavior is followed by assessment from the main instructor (GI, GG).

\subsubsection{Cooperative Preadolescent Level}

The cooperative activities generate antecedent behaviors of Individual and Group Guide (GI, GG) from the Main Instructor and the Secondary Instructor (belonging to the Assessment Function) (see table number 5).

It must be noted that in this type of activities, the secondary instructor generates antecedent behavioral patterns, which does not happen in the intrapersonal and interpersonal activities. The cooperative activities are developed at the end of the program, when the secondary instructor shows a higher level of participation. This might be due to the fact that the secondary instructor might have gained experience, without affecting the main instructor's role. However, the secondary instructor's behavioral patterns do not generate any response from the participants whereas the main instructor's does.

When the secondary instructor does a Group Guide (GG), this behavior generates the same behavior by the main instructor (GG), Participants Disruptions (DP) and Instrumental Behavior (Y) in the secondary instructor.

The Interaction Function includes the behavior of the participants. When cooperative activities are performed, antecedent behaviors of participants generate lots of behaviors, including the participation of the secondary instructor (encouragement, guides, explanations, organization behaviors, general interactions). However, an improper conduct appears, the General Interactions (IG), which involves interactions unrelated to the activity that is being performed 
and disrupts the normal development of the sessions of the program.

Table 5. Preadolescent Level(Cooperative area, results by codes)

\begin{tabular}{|c|c|c|c|}
\hline \multirow{2}{*}{$\begin{array}{l}\text { Teaching } \\
\text { Functions }\end{array}$} & \multirow{2}{*}{ Antecedent behavior } & \multicolumn{2}{|c|}{ Consequent behavior } \\
\hline & & Lag 1 & Residual \\
\hline \multirow{9}{*}{$\begin{array}{l}\text { Assessment } \\
\text { Function }\end{array}$} & \multirow{3}{*}{ GI M-I } & OA M-I & 2.166 \\
\hline & & RN M-I & 2.980 \\
\hline & & RP P & 11.067 \\
\hline & \multirow{3}{*}{ GG M-I } & OD M-I & 2.998 \\
\hline & & Y M-I & 2.238 \\
\hline & & RG S-I & 2.303 \\
\hline & \multirow{3}{*}{ GG S-I } & GG M-I & 2.093 \\
\hline & & Y S-I & 2.222 \\
\hline & & DP $\mathbf{P}$ & 2.373 \\
\hline \multirow{14}{*}{$\begin{array}{c}\text { Interaction } \\
\text { Function }\end{array}$} & \multirow{6}{*}{ DM P } & IG P & 11.105 \\
\hline & & RI S-I & 3.863 \\
\hline & & GI S-I & 2.880 \\
\hline & & OD S-I & 2.511 \\
\hline & & EI S-I & 5.476 \\
\hline & & RN S-I & 7.045 \\
\hline & \multirow{5}{*}{ RP P } & RI M-I & 2.513 \\
\hline & & GI M-I & 11.745 \\
\hline & & GG M-I & 2.256 \\
\hline & & GI S-I & 3.642 \\
\hline & & GG S-I & 2.275 \\
\hline & \multirow{3}{*}{ IG P } & EG M-I & 2.566 \\
\hline & & IG M-I & 27.651 \\
\hline & & IG S-I & 9.205 \\
\hline
\end{tabular}

The general interactions are considered as the participants antecedent behavioral patterns. These ones elicit General Interactions (IG) between both instructors and the participants, as well as the main instructor's Group Explanation (EG).

The rest of the behavioral patterns still remain the same, but it must be pointed out that the main instructor has a higher level of participation when leading and encouraging the participants.

\section{Discussion}

Undoubtedly, the power that the observational methodology has when it comes to gathering the human behavior in natural situations, for instance, the behavior of the psychoeducational instructor in an out-of-school program of high abilities is remarkable. Through this methodology, detailed and precise information about the behavior of the program PIPAC instructors has been obtained.

This methodology has allowed us to know the role of the two instructors of the preadolescent program PIPAC level when they develop intrapersonal, interpersonal and cooperative activities. Firstly, it is important to note that the frequency of occurrence of behaviors gives the main instructor the responsibility to implement the program. This tells us that the main instructor is responsible for guiding the group and the role played by the secondary instructor is secondary and supports the tasks performed by the main instructor. The main instructor is responsible for guiding the group in intrapersonal and interpersonal activities. In cooperative activities, the secondary instructor takes a more active role guiding the group of children.

Sequential analysis allows to dynamically understand what happens within an intervention program, permitting the 
removal of those patterns of behavior that lead both to adequate and inadequate patterns, from the point of view of the teaching-learning process.

This analysis generates behavioural patterns. The most frequent patterns in the program are the teacher's behaviour which generates assessment. This behaviour promotes the interaction among the participants thorough individual guidance (GI). On the students side it promotes questions (RP) and answers (DM) to the teacher. This type of pattern "the assessment function followed by the interaction function" gives high interaction. This pattern can also be bidirectional "The interaction function followed by the assessment function"

An important aspect of this type of analysis is that it has allowed us to see the evolution that occurs in the conduct of the secondary instructor during the sessions of the program. Her behavior is aimed to support tasks that the main instructor performs, and the frequency of her behavior is not high enough to be taken as a criteria conduct. When the program is coming to an end and cooperative activities are being done, there is a greater involvement of the secondary instructor. This increased participation is due to the secondary instructor having greater experience in the group, and that translates into greater responsibility for guiding the group of children in the sessions of the program.

The sessions of the program are designed as short activities with clear objectives focused in affective aspects. This encourages an effective action of the instructors, where most of the behaviors and the time of the intervention session are intended to guide, help organize and asses the process of teaching and learning, as well as to motivate the participants (Van de Grift, 2007).

Therefore, this study has allowed finding the wealth of information extracted through an observation instrument for the conduct of the instructors of an after-school program. This instrument not only gives detailed information that happens within the sessions of intervention of the programme, but also improvement plans for the teacher's performance can be introduced through the analysis (Wankat \& Oreovicz, 1993; Cosser, 1998; Shortland, 2004).

Programs evaluation, in this case the process evaluation, allows us to make recommendations and suggestions for improvements to the program. The motivational function does not appear until the cooperative activities. It is therefore important that the instructors give more reinforcement since it encourages the children to participate and be involved in the activities. It is also important that the communication between both instructors is encouraged so as to promote coordination in the behaviors that they develop with the group, as well as to clearly plan each of the program activities without straying from the proposed objective to avoid improper behaviors appearing when the activities are being developed as it is the case of the General Interactions (IG).

\section{References}

Aguilar, M.J., \& Ander-Egg, E. (1992). Evaluación de servicios y programas sociales. Madrid: Siglo XXI.

Alonso, J.A., \& Benito, Y. (1996). Superdotados: Adaptación escolar y social en Secundaria. Barcelona: Narcea.

Anguera, M.T., Blanco, A., \& Losada, J.L. (2001). Diseños observacionales, cuestión clave en el proceso de la metodología observacional. Metodología de las Ciencias del Comportamiento, 3(2), 135-160.

Arancibia, V., Lissi, M.R., \& Narea, M. (2008). Impact in the school system of a strategy for identifying and selecting academically talented students: the experience of Program PENTA-UC. High Ability Studies, 19(1), 53-65. http://dx.doi.org/10.1080/13598130801980331.

Bakeman, R., \& Quera, V. (1996). Análisis de la interacción. Análisis Secuencial con SDIS y GSEQ. Madrid: Ra-Ma.

Borges, A., \& Rodríguez-Naveiras, E. (2012). Programas de intervención en altas capacidades y su evaluación. En M.D. Valadez, J. Bethancourt y M.A. Zavala (Eds.), Alumnos superdotados y talentosos. Identificación, evaluación e intervención. Una perspectiva para docentes (pp. 405-408). México: Manual Moderno.

Borges, A., \& Rodríguez-Naveiras, E. (2014). Una década del Programa Integral para Altas Capacidades: origen, desarrollo y evaluación. IX Congreso Iberoamericano de Psicología. Lisboa.

Borrie, A., Jonsson, G.K., \& Magnusson, M.S. (2001). Application of T-pattern detection and analysis in sports research. Metodología de las Ciencias del Comportamiento, 3(2), 215-226.

Brophy, J. E., \& Evertson, C. M. (1976). Learning from teaching: a developmental perspective. Boston, MA: Allyn \& Bacon.

Cassady, J. C., Neumeister, K. L., Speirs, A., Cheryll M., Cross, T. L., Dixon, F. A., \& Pierce, R. L. (2004). The diffentiated classroom observation scale. Roeper Review, 26(3), 139-146. http://dx.doi.org/10.1080/02783190409554259 
Colás, M.P., \& Rebollo, M.A. (1993). Evaluación de programas: Una guía práctica. Sevilla: Kronos.

Cooper, J. M. (1993). El maestro y la toma de decisiones. En J. M. Cooper (Eds.), Estrategias de enseñanza: Guía para una mejor instrucción. Méjico: Limusa.

Cosser, M. (1998). Towards the design of a system of peer review of teaching for the advancement of the individual within the university, Higher Education, 35, 143-162. http://dx.doi.org/10.1023/A:1003155703281

Díaz Hernández, M. (2014). Protocolo de Observación de Funciones Docentes en Universidad: Un instrumento para la evaluación de la conducta del profesorado universitario. Tesis Doctoral. La Laguna: Universidad de La Laguna. Servicio de Publicaciones.

Díaz, O., \& Bravo, A. (2002). Programa de Enriquecimiento de ASAC (Asociación de altas capacidades). Faisca. Revista de Altas Capacidades, 9, 11-125.

Evertson, C. M., \& Anderson, L. M. (1978). Interim progress report: the classroom organization study. Austin, TX: University of Texas.

Feldhusen, J., \& Hoffman, L. (1988). Practicum experiences in an education program for teachers of the gifted. Journal for the Education of the Gifted, 12, 34-45.

Flanders, N. A. (1961). Interaction analysis: a technique for quantifying teacher influence. Minneapolis, MN: University of Minnesota, College of Education, Bureau of Educational Research.

Gil Galve, A. (2008) Los porteros de Futbol, ¿se comportan como sistemas complejos? Tesis Doctoral. Universidad de Barcelona.

Guerrero, A. (2009). El docente: características, funciones y eficacia. Revista digital: Innovación y experiencias educativas, 24, 1-10.

Hernández, P. (1991). Psicología de la Educación: corrientes actuales y teorías aplicadas. Méjico: Trillas.

Hernández, P., \& García, L. A. (1991). Psicología y enseñanza del estudio. Madrid: Pirámide.

Hernández-Jorge, C. (2005). Habilidades de comunicación para profesionales. Tenerife: ARTE: Comunicación visual.

Houtveen, A. A. M., Booij, N., de Jong, R., \& Van de Grift, W. J. C. M. (1999). Adaptive instruction and pupil achievement. School Effectiveness and School Improvement, 10(2), 172-192. http://dx.doi.org/10.1076/sesi.10.2.172.3508

Justicia, F. (1996). El profesor: los procesos de pensamiento. En A.Barca, J.A. González-Pienda, R. González and J. Escoriza (Eds.), Psicología de la Instrucción. Vol. 3: Componentes contextuales y relacionales del aprendizaje escolar. Barcelona: EUB.

Kulieke, M. (1986). The role of evaluation in service and staff development for educators of the gifted. Gifted Child Quartely, 30, 140-144. http://dx.doi.org/10.1177/001698628603000311

López de la Llave, A., \& Pérez-Llantada, M.C. (2004). Evaluación de programas en psicología aplicada (salud, intervenciones sociales, deporte, calidad). Madrid: Dykinson.

Newcomer, K., Hatry, H., \& Wholey, J. (2010). Planning and designing useful evaluations. In Wholey, J., Hatry, H. \& Newcomer, K. (2010), Handbook of practical program evaluation (pp. 48-73). Francisco: JOSSEY-BASS A Wiley Imprint.

Prieto, M.D., \& Ferrándiz, C. (2001). Inteligencias Múltiples y curriculum escolar. Málaga: Aljibe.

Renzulli, J. S. (1977). The enrichment triad model: A plan for developing defensible programs for the gifted and talented: II. Gifted Child Quarterly, 21(2), 227-233.

Rodríguez, G.., \& Ibarra, M. S. (2013). La evaluación de los procesos y contextos educativos. En F. Navaridas (Coord.). Procesos y contextos educativos: nuevas perspectivas para la práctica docente (pp. 257-294). Logroño: Genueve Ediciones.

Rodríguez-Naveiras, E. (2011). PROFUNDO: Un instrumento para la evaluación de proceso de un programa de altas capacidades. Tesis Doctoral. La Laguna: Universidad de La Laguna. Servicio de Publicaciones.

Rodríguez-Naveiras, E., Borges, A., \& Cadenas, M. (2013). Creating and Purifying an Observation Instrument Using the Generalizability Theory. Acción Psicológica, 10(2), 73-86. http://dx.doi.org/10.5944/ap.10.2.11825 
Romero, G. A. (2010). Experiencia educativa: la actitud del profesor en el aula. Revista Digital: Innovación y Experiencia Educativas, 27, 1-8.

Rossi, P. H., Lipsey, M.W., \& Freeman, H.E. (2004). Evaluation. A Systematic Approach. $7^{\circ}$ edn. Thousand Oaks, CA: Sage Publications Inc. Sackett, G.P. (1979). The lag sequential analysis of contingency and ciclicity in behavioral interaction research. In J. Osofsky (Ed.), Handbook of infant development, (pp. 623-649). Nueva York: Wiley.

Sackett, G.P. (1979). The lag sequential analysis of contingency and ciclicity in behavioral interaction research. In J. Osofsky (Ed.), Handbook of infant development, (pp. 623-649). Nueva York: Wiley.

Shiratuddin, N., \& Landoni, M. (2002). Evaluation of content activities in children's educational software. Evaluation and Program Planning, 25(2), 175-182. http://dx.doi.org/10.1016/S0149-7189(02)00011-3

Shortland, S. (2004). Peer observation: a tool for staff development or compliance? Journal of Further and Higher Education, 28(2), 219-228. http://dx.doi.org/10.1080/0309877042000206778

Tricket, E. J., \& Moos, R. H. (1974). The Classroom environment scale (CES). Palo Alto, CA: Consulting Psychologists Press, Inc.

Van de Grift, W. (2007). Quality of teaching in four European countries: a review of the literature and application of an assesment instrument. Educational Research, 49(2), 127-152. http://dx.doi.org/10.1080/00131880701369651

VanTassel-Baska, J. Quek, C., \& Feng X. (2007). The development and use of a structure teacher observation scale to assess differentiated best practice. Roeper Review, 29, 84-92. http://dx.doi.org/10.1080/02783190709554391

Veney, J.E., \& Kaluzny, A.D. (1984). Evaluation and Decision Making for Health Services Program. Englewood Cliffs: Prentice-Hall. Watkins, D. A. y Biggs, J. B. (1996). The Chinese learner: cultural, psychological and contextual influences. Hong Kong: CERC/ACER.

Wankat, P. C., \& Oreovitz, F. S. (1993). Teaching engineering. Nueva York: McGraw-Hill.

Watkins, D. A., \& Biggs, J. B. (1996). The Chinese learner: cultural, psychological and contextual influences. Hong Kong: CERC/ACER. 